\title{
PATRIMONIO DE LA GUERRA CIVIL ESPAÑOLA: EL FRENTE SUR DEL TAJO
}

\author{
Luis Antonio Ruiz Casero ${ }^{1}$
}

\section{Resumen:}

Tras el levantamiento del asedio del Alcázar de Toledo en septiembre de 1936 se establecieron dos cabezas de puente al sur del Tajo. El general Yagüe proyectaría su ampliación para evitar el hostigamiento de los republicanos contra la ciudad, lo que ocasionaría una dura batalla entre los días 7 y 13 de mayo de 1937. El frente, estabilizado hasta 1939, nos ha legado un abundante patrimonio.

\section{Palabras clave:}

Guerra civil, Toledo, Frente Sur del Tajo, patrimonio, musealización.

\begin{abstract}
:
After the relief of the Siege of the Alcázar of Toledo on September 1936, two bridgeheads were established at the southern bank of the Tagus river. General Yagüe proposed their enlargement in order to avoid the republicans' harass against the city, causing a hard battle on May 7th-13th, 1937. The front, that remained stabilized until 1939, left behind a large amount of military heritage.
\end{abstract}

\section{Key words:}

Spanish Civil War, Toledo, Tajo’s South Front, heritage, musealizing.

La comunicación presentada tiene un doble origen. Por una parte, el Trabajo de Fin de Máster del ponente, leído el 27 de septiembre de 2011 en la Facultad de Filosofía y Letras de la Universidad de Alcalá; ${ }^{2}$ y, por otro, la colaboración con el proyecto "Paisajes culturales de la ciudad de Toledo: los Cigarrales". El estudio de la Guerra Civil española en el Frente Sur del Tajo en los últimos años ha tenido un desarrollo notable, que se ha plasmado en una cantidad nada desdeñable de publicaciones y conferencias $^{3}$. Se trata, además, de un proyecto vivo, cuya difusión sigue en curso.

\footnotetext{
1 Investigador independiente/ Departamento de Arqueología de AUDEMA.

2 El trabajo fue editado en la Colección Toledo: Paisajes. Textos universitarios: Los combates al Sur del Tajo: Un enfoque patrimonial de un escenario de la Guerra Civil. Madrid, 2014

3 Carrobles, J. y Morín, J -eds.-, Los paisajes culturales de la ciudad de Toledo. Dehesas, espacios irrigados, torres, cigarrales y trincheras. BAR Internacional Series 2638. Oxford, 2014; Barroso Cabrera R. et al. "Arqueología de la Guerra Civil en Toledo. El Frente Sur del Tajo y el Cigarral de Menores: un escenario de guerra", Archivo Secreto. Revista Cultural de Toledo, 5, 2011, pp. 330-348 y La Guerra Civil en Toledo: El Frente Sur del Tajo. Metodología para el estudio de un frente de la guerra civil española, en VII Jornadas del Patrimonio Arqueológico de la Comunidad de Madrid (Madrid, 2010). Madrid, 2014, pp. 327-399
} 
El trabajo del ponente en el seno de dicho proyecto se centró en una triple vertiente. Por una parte, la reconstrucción historiográfica de los combates más importantes acaecidos en el sector toledano, centrándose especialmente en los episodios de mayo de 1937, olvidados por la historia de la contienda; por otra, en un inventario exhaustivo de los restos que nos legó el frente de Toledo; y, por último, en una propuesta de musealización y conservación de ese patrimonio, seriamente amenazado.

\section{La guerra civil en toledo}

El escenario bélico que nos ocupa -el Frente Sur del Tajo- nació en octubre de 1936, con la conquista de la ciudad de Toledo por parte de las columnas africanas al mando de Franco y Varela, desviadas de la marcha hacia Madrid para liberar a los asediados en el Alcázar bajo el mando de Moscardó. Al tomarse la ciudad, se aseguraron unas pequeñas cabezas de puente, porciones de territorio franquista en la orilla sur del río Tajo (republicana) en torno a los puentes históricos de la ciudad: Alcántara y San Martín.

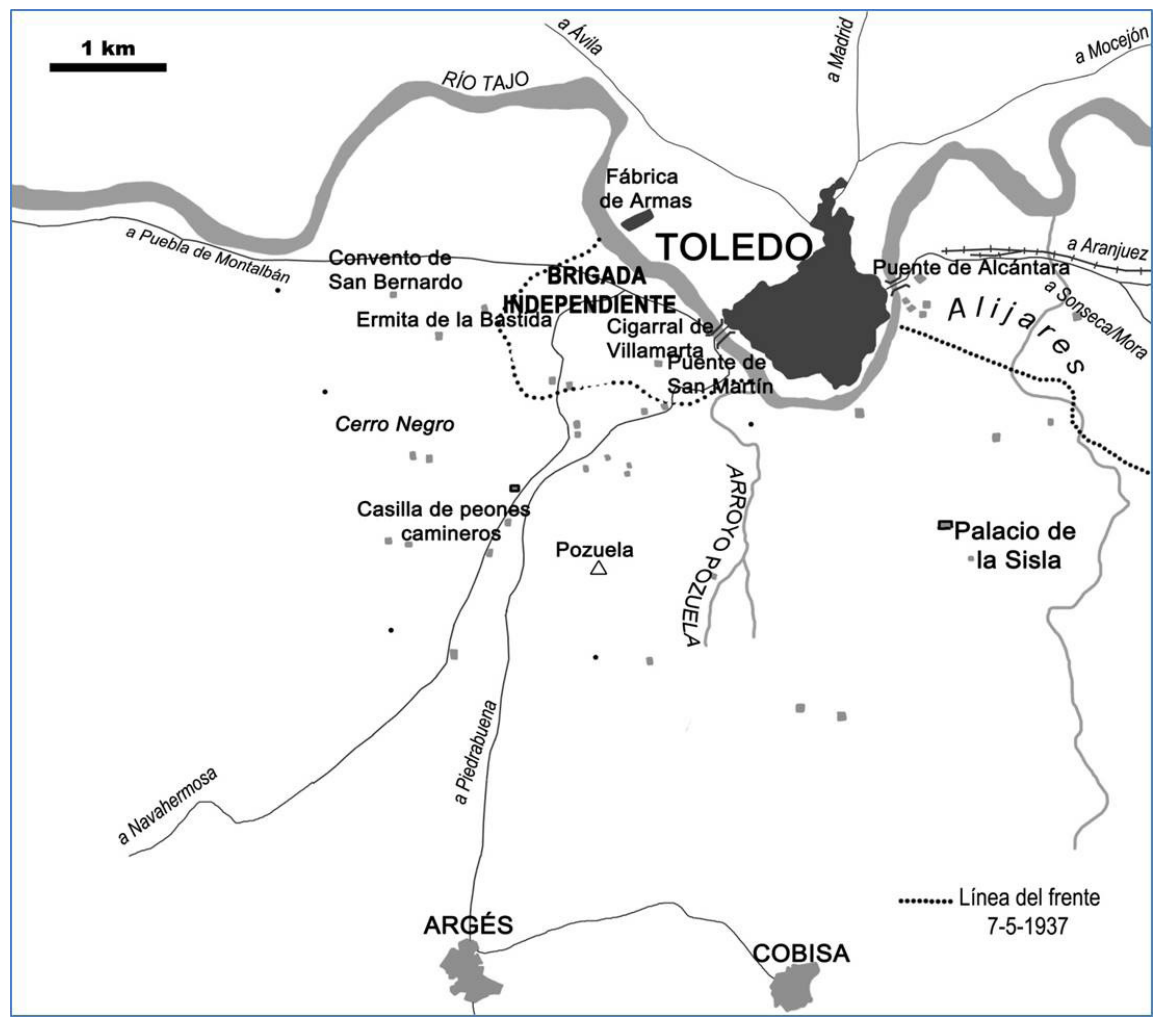

Fig. 1. Toledo a principios de 1937 y sus cabezas de puente. 
Desde ese momento hasta el final de la guerra, el Frente Sur del Tajo permaneció anclado en una estabilidad relativa, interrumpida por estallidos puntuales, breves pero de gran violencia, siendo los más notables los episodios de mayo y septiembre de 1937 (batalla del Sur del Tajo y unificación de las cabezas de puente de Toledo), marzo de 1938 (ataque contra la Atalaya de las Nieves), y marzo de 1939 (Ofensiva final o "de la Victoria") ${ }^{4}$. Dicha estabilidad, así como la relevancia estratégica de la zona -que permaneció siempre en la mente de los estrategas del conflicto como una perfecta base para emprender operaciones de gran alcance, que sin embargo no se materializarían hasta el final mismo de la guerra-, trajo aparejada una intensa labor de fortificación por parte de ambos bandos.

\section{La batalla del Sur del Tajo}

Dado lo inabarcable del territorio cubierto por el frente (varias decenas de kilómetros de trincheras solo en el término municipal de Toledo), la labor de documentación y estudio se circunscribió al territorio de la cabeza de puente de San Martín, escenario de la batalla de mayo de 1937: la batalla del Sur del Tajo.

Dicho enfrentamiento constituyó la mayor de las batallas acaecidas en ese frente, y una de las principales "batallas menores" de la Guerra Civil española. En el transcurso del trabajo se reparó en el gran vacío historiográfico del que dichos combates habían sido objeto, por lo que se consideró de suma importancia estudiarlos en profundidad como paso previo a cualquier otro. ${ }^{5}$

A grandes rasgos, la secuencia de los hechos fue la siguiente.

Cada una de las cabezas de puente formadas en septiembre de 1936 se correspondía con uno de los puentes históricos toledanos, Alcántara y San Martín. La situación táctica de Toledo era muy precaria. Las cabezas de puente, conformadas apresuradamente, estaban separadas entre sí por una cuña de más de mil quinientos metros de territorio republicano en la zona de la Sisla. En el sector de San Martín, al oeste, la zona bajo el control de los nacionales penetraba alrededor de un kilómetro en los dominios enemigos, y dejaba tanto la Fábrica de Armas -que los franquistas habían vuelto a poner en funcionamiento al poco de la conquista de la ciudad- como el propio casco urbano de Toledo a simple vista de los observatorios republicanos.

Era, por tanto, más que previsible un ataque artillero contra la fábrica toledana,

4 Las operaciones fueron investigadas por Martínez Bande, J. M., La batalla de Pozoblanco y el cierre de la bolsa de Mérida, en Monografías de la Guerra de España, nº 15, Madrid, 1981, y, más recientemente, por Ruiz Alonso, J. M. , La guerra civil en la provincia de Toledo: Utopía, conflicto y poder en el sur del Tajo (1936 - 1939), Ciudad Real, 2004.

5 El estudio historiográfico ha resultado recientemente en la publicación de una monografía: Ruiz Casero, L. A., Más allá del Alcázar. La batalla del Sur del Tajo. Toledo y Argés, 1937, Guadalajara, 2015. 
aunque poco se hizo por evitarlo. Manuel Uribarri, antiguo teniente coronel de la Guardia Civil al mando de la 46 a brigada mixta republicana, logró reunir algunas piezas (el frente Sur del Tajo era conocido por la falta de medios imperante en ambos bandos) y emprender un bombardeo de castigo que el 19 de abril de 1937 destruyó parcialmente las naves de la fábrica.

El coronel Yagüe, por aquel entonces a cargo de la $4^{\text {a }}$ división franquista que cubría el frente de Toledo, se puso de inmediato a trabajar en un plan para expulsar al enemigo de las cercanías de la ciudad, y así evitar el tiro directo sobre la misma. Propuso a su superior, el general Saliquet, unificar las cabezas de puente y arrebatar al enemigo sus observatorios artilleros. Pretendía ejecutar una acción relámpago, para la que necesitaría entre seis y ocho batallones de infantería y varias baterías.

La operación propuesta se topó con el conservadurismo militar de Saliquet, que se negó a prestar las fuerzas necesarias. Aprobó una versión mutilada del plan de Yagüe, lo que lastró el ataque desde el principio. Sólo se ampliaría una de las cabezas de puente, la de San Martín. Se alejaría el frente de la ciudad, pero el enemigo seguiría contando con observatorios desde los que la podría divisar a simple vista. Yagüe estaba furioso, pero hubo de tragarse el orgullo y resignarse, con la vaga esperanza de que, una vez sus tropas estuviesen sobre el terreno y se apreciase que el esfuerzo había sido en gran medida inútil, Saliquet diese su brazo a torcer.

El plan definitivo contemplaba el empleo de varios batallones de choque y cinco baterías artilleras, elementos que darían a Yagüe una amplia superioridad local y que permitirían conservar el elemento sorpresa y la ruptura rápida que proponía su plan original. El día 25 de abril la orden de operaciones llegó al cuartel general de Saliquet, que aprobó su ejecución para el día 7 de mayo.

El teniente coronel Esteban-Infantes, toledano de nacimiento y conocedor del campo de batalla, fue el encargado de mandar las tropas sobre el terreno, encuadradas en una brigada independiente. La componían dos banderas de la Legión (la I y la VIII), los dos tabores de Ifni entonces disponibles (el de Ifni-Sáhara y el batallón de Tiradores), y dos batallones de infantería (el $3^{\circ}$ del Regimiento La Victoria y el $1^{\circ}$ de Mérida). Como apoyo, las fuerzas divisionarias que guarecían la ciudad de Toledo (el $8^{\circ}$ batallón de Bailén y el $1^{\circ}$ de Voluntarios de Toledo), así como dos compañías de zapadores y abundante artillería (un grupo de 75 mm., dos baterías de $105 \mathrm{~mm}$. y una de $155 \mathrm{~mm}$.). Ante ellos, las desorganizadas tropas de la 46 brigada mixta de Uribarri, que apenas habían superado el estatus miliciano, encuadradas en el VII Cuerpo que mandaba el coronel Mena.

Durante la noche del 6 de mayo las tropas atravesaron el puente de San Martín para ocupar sus bases de partida. Varios miles de hombres a pie, acompañados de la impedimenta en caballerías, camiones con artillería y demás pertrechos atravesaron el estrecho puente medieval y se desplegaron del otro lado, entre los 
históricos Cigarrales, las fincas de recreo del Siglo de Oro que jalonan el paisaje ondulado del sur del Tajo. La marcha se hizo bajo estrictas órdenes de discreción y silencio.

Antes del amanecer, llegó la orden de avance. Las tropas, desplegadas en abanico, con los batallones de choque como punta de lanza, sorprendieron por completo a los republicanos. El pánico se extendió entre los batallones de la 46 brigada. Esteban-Infantes había asignado a cada una de sus unidades unos objetivos, posiciones de batallón numeradas del 1 al 8, en sentido antihorario. Todas se fueron alcanzando a lo largo de la mañana: la VIII bandera del Tercio tomó la posición número 1, cerca de la orilla del Tajo. La I bandera, las posiciones 3 y 4. El batallón Mérida alcanzó las posiciones 5 y 6 , y los Tiradores de Ifni las numeradas con el 7 y el 8 . El tabor de Ifni-Sáhara marchó hacia el este, para establecerse más allá del Arroyo Pozuela, con la misión de guardar el flanco izquierdo durante el avance. El batallón de la Victoria quedó como reserva, junto a las unidades de zapadores.

La minuciosa planificación dio sus frutos: la resistencia enemiga fue testimonial, y las bajas muy reducidas. Yagüe, sin embargo, no echaba las campanas al vuelo. Aún dudaba si se le permitiría unificar más adelante las dos cabezas de puente. Sus esperanzas se revelarían vanas.

Entretanto, las noticias llegaban con cuentagotas a los puestos de mando republicanos. Mena, jefe del sector, estaba en Cabeza del Buey, a trescientos kilómetros de Toledo. A medida que se ascendía en el escalafón, la niebla de la guerra fue convirtiendo la operación local de Yagüe en una ofensiva en toda regla. Cuando las informaciones alcanzaron Madrid, el Estado Mayor del Ejército del Centro creyó que se ha producido una ruptura total del frente. Se pensaba que el enemigo pretendía llegar hasta Tembleque en un intento más de aislar la capital de la retaguardia que la abastecía, como en el Jarama y en Guadalajara. Vicente Rojo resolvió enviar al Sur del Tajo un fuerte contingente para detener la supuesta ofensiva: las tropas de choque de la división de Líster, acompañadas por una brigada de nueva creación, la 113 . Cerca de diez mil hombres. Y tanques, blindados, artillería y aviación.

La contraofensiva se puso en marcha al amanecer el día 9. Mena dividió las numerosas tropas puestas bajo su mando en tres Agrupaciones y una reserva:

- Izquierda (Líster), formada por la $11^{a}$ división y un grupo de tanques T-26 del $1^{\circ}$ batallón.

- Centro (Mejide), con dos batallones de la $46^{a}$ brigada, uno de la $113^{a}$ y otro de la $45^{a}$, este último como reserva.

- Derecha (Pando), con los dos batallones restantes de la 46a ${ }^{a}$, uno de la $45^{a}$ y una compañía de autoametralladoras, así como el apoyo de un tren blindado. 
- Reserva general: los tres batallones restantes de la $113^{\mathrm{a}}$ brigada.

El primer empujón de la contraofensiva sorprendió a las avanzadillas franquistas, que cedieron terreno al sur y al oeste de la cabeza de puente. El pueblo de Argés fue retomado por los republicanos. No se esperaba un contraataque de tal magnitud, y el gobernador militar de Toledo, el teniente coronel habilitado GuiIlermo Emperador, tuvo que asumir la defensa, pues Esteban-Infantes ya se encontraba muy lejos del frente. Emperador, que hasta el momento no había mandado efectivos superiores a un batallón, se vio abrumado por la situación, y en seguida Ilegaron a Yuncos, cuartel general de Yagüe, las Ilamadas angustiosas solicitando refuerzos, que se enviario de inmediato: la compañía de de la Academia de Infantería, la II bandera de Falange de Castilla y las IV y VI banderas de la Legión, así como abundante artillería.

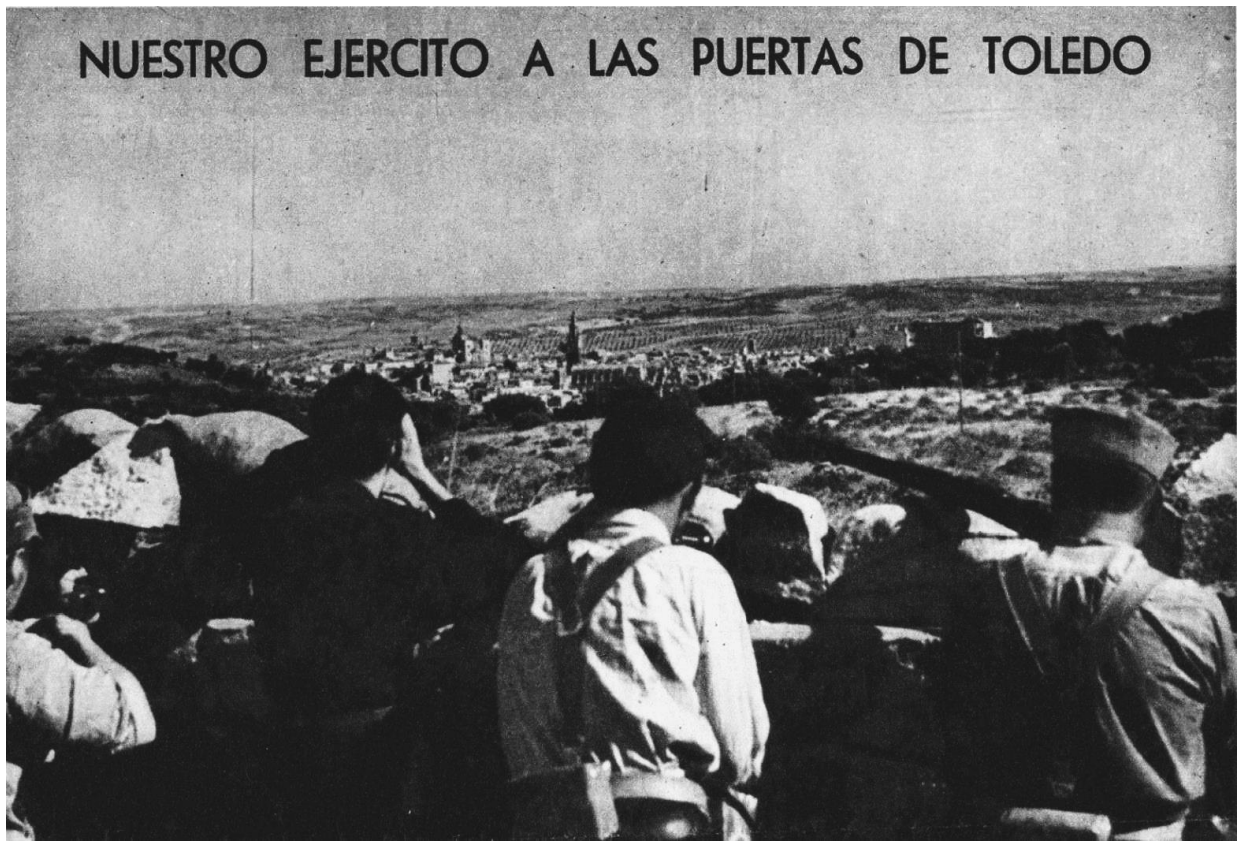

Fig. 2. Las tropas republicanas, a escasos kilómetros del centro de Toledo.

A la mañana del día 10, los republicanos retomaron el avance, precedidos por el bombardeo artillero y los T-26. Las posiciones más disputadas eran las numeradas con el 4 y el 5, en torno a lo que los atacantes Ilamaban el "Cerro Negro", pero, sobre todo, el sector de Pozuela (posiciones número 7 y 8). Los Tiradores de Ifni y el Batallón Mérida que lo defendían, perdieron el temple y huyeron. Los republicanos habían logrado poner el pie en las trincheras. 
La VI bandera fue enviada a retomar las posiciones perdidas. La $22^{a}$ compañía atacó desde el flanco izquierdo, poniendo en fuga a la mayor parte de los nuevos ocupantes. Un grupo que resistía fue exterminado con bombas de mano. Una vez retomada la posición, todas las bocas de fuego disponibles en el lado republicano se concentraron sobre la misma, precediendo a la infantería. Las compañías $21^{\text {a }}$ y $24^{\mathrm{a}}$, enviadas a reforzar la posición, descubrieron que las defensas estaban, en gran parte, destruidas. Casi no quedaban ametralladoras útiles. La $21^{\text {a }}$ fue muy castigada, y sufrió un conato de desbandada abortado en seguida, pistola en mano, por sus oficiales. Desde la inmediata segunda línea, el comandante Fernández Cuevas apuraba las reservas. Ni siquiera su puesto de mando estaba a salvo, pues su segundo al mando, el comandante Ramírez, cayó herido por bala de fusil.

Al caer la noche, la posición continuaba en manos de la VI bandera, pero las bajas habían sido elevadas en toda la línea. La II bandera de Castilla, con abundantes bajas, entre ellas la de su jefe, fue enviada a retaguardia. Durante la jornada hubo pequeños éxitos locales: se derribó un avión republicano, y los Tiradores de Ifni lograron capturar un T-26, pero la situación general era crítica. Si el Vértice Pozuela caía en manos enemigas, todo el frente se podría desmoronar.

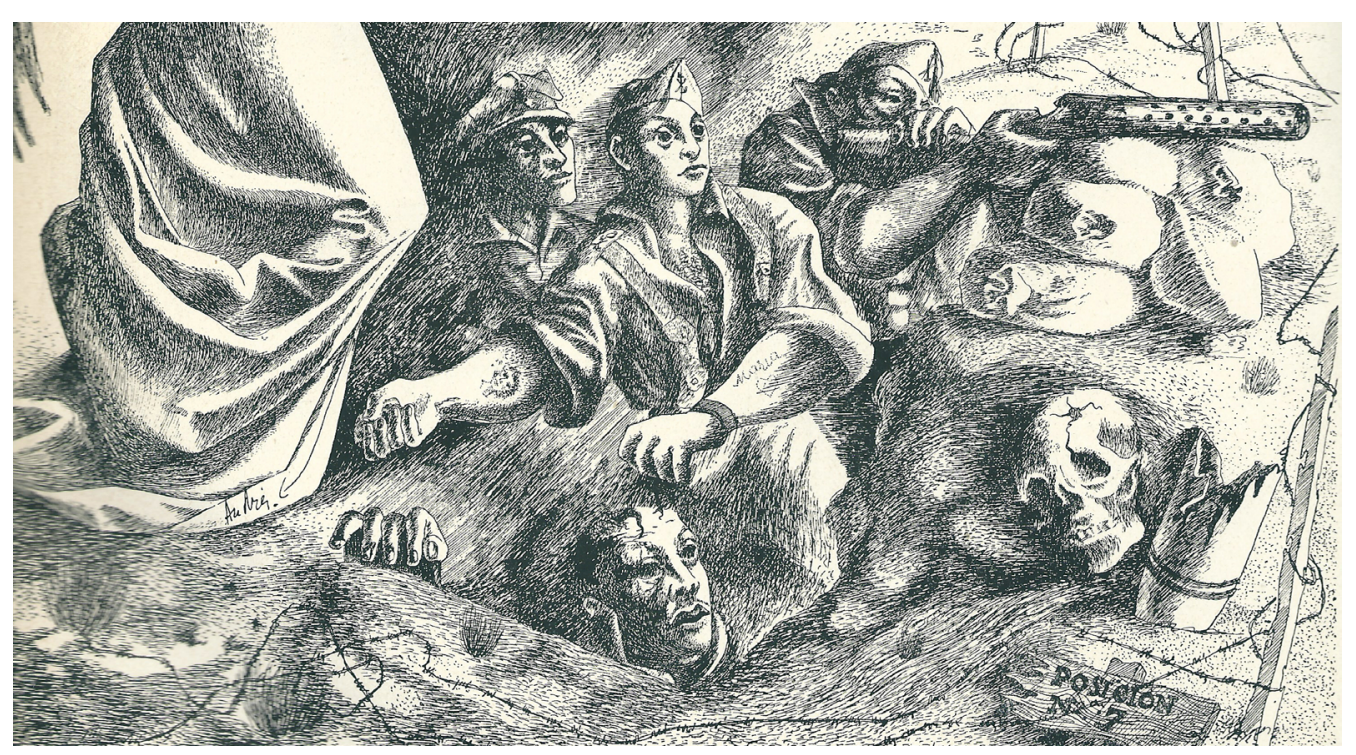

Fig. 3. Alegoría franquista de la defensa de la "posición número 7".

La jornada del día 11 fue la más dura de la batalla. Las barreras artilleras nacionales lograron detener el avance del flanco derecho, aunque, en el izquierdo, las tropas de Pando conquistaron el palacio de la Sisla. Sin embargo, la llave del sector fue, como en el día anterior, la posición número 7. 
Los cañones y morteros republicanos de todo el sector concentraron sus proyectiles contra la VI bandera. Su comandante, Fernández Cuevas, caía herido a las diez de la mañana, pero no se le pudo evacuar: los caminos estaban cortados por los embudos de artillería. Se llegó al cuerpo a cuerpo, y la posición se perdió de nuevo. La $21^{\text {a }}$ compañía fue enviada en un asalto desesperado a retomarla a pecho descubierto. El alférez al mando de la $3^{\text {a }}$ sección, Orozco Massieu, llevó el peso de la lucha. Herido de metralla en la cabeza, continuó luchando y animando a sus hombres a resistir los sucesivos asaltos republicanos. Ni siquiera quedaban bombas de mano para rechazar a los T-26, y Orozco exhortaba a los legionarios a disparar sus fusiles contra las mirillas. En ese momento cae herido por segunda vez, en el pecho. Malherido, se resiste a ser evacuado. Su sección sufrió un 75\% de bajas, pero mantuvo el tipo. El sexto asalto republicano se repelió por pura terquedad. Frente a la posición número siete se amontonan los cadáveres enemigos. Afortunadamente cae la noche, y con ella el relevo.

La simbólica ciudad de Toledo quedaba así a salvo del enemigo. Los combates, que irían decreciendo hasta agotarse el día 12, habían alcanzado momentos de una dureza atroz: Yagüe declararía que al Sur del Tajo le tocó resolver "una papeleta más dura que la del Pingarrón". Los legionarios de la VI bandera podían dar testimonio de ello con su sacrificio, digno de la más alta condecoración. La Laureada de San Fernando le sería concedida a la bandera el 2 de noviembre, y la Laureada Individual al alférez Orozco el 19 de febrero de 1939.

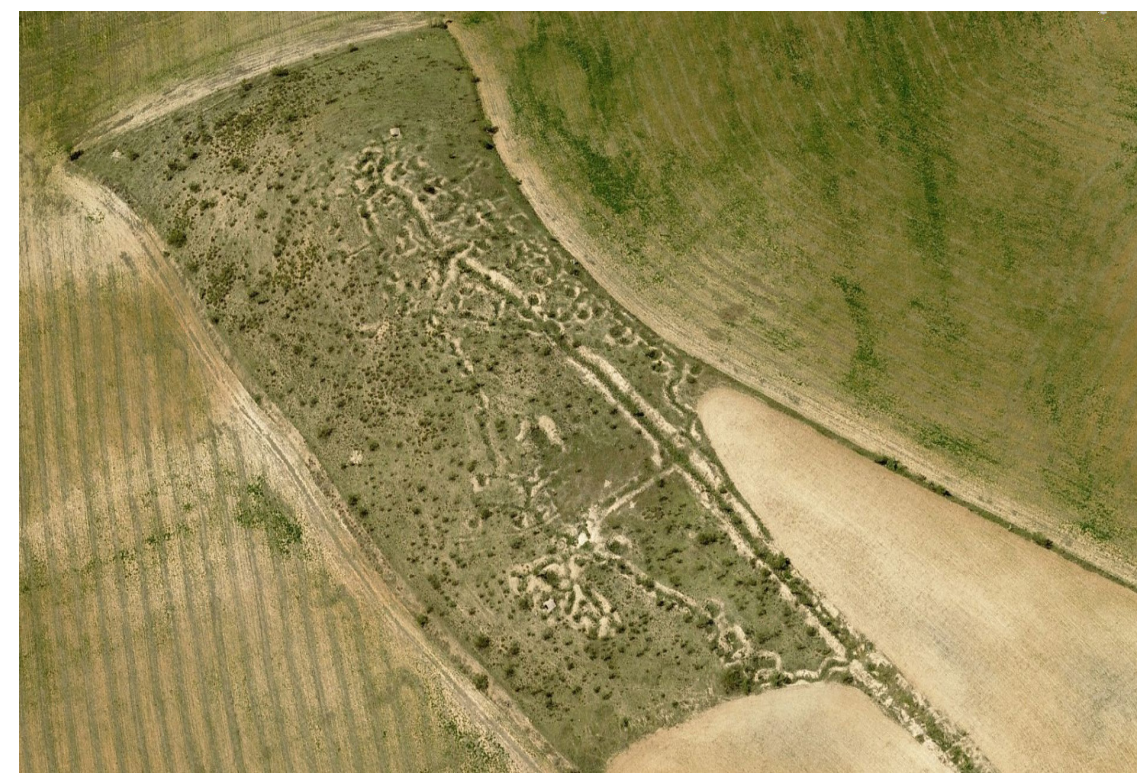

Fig. 4. Fotografía aérea de la "posición número 7" en la actualidad. 


\section{Inventario de restos}

Se presenta a continuación un intento de sistematizar y completar el inventario de estructuras relacionadas con la Guerra Civil asociadas a la cabeza de puente de San Martín y a los combates que allí ocurrieron.

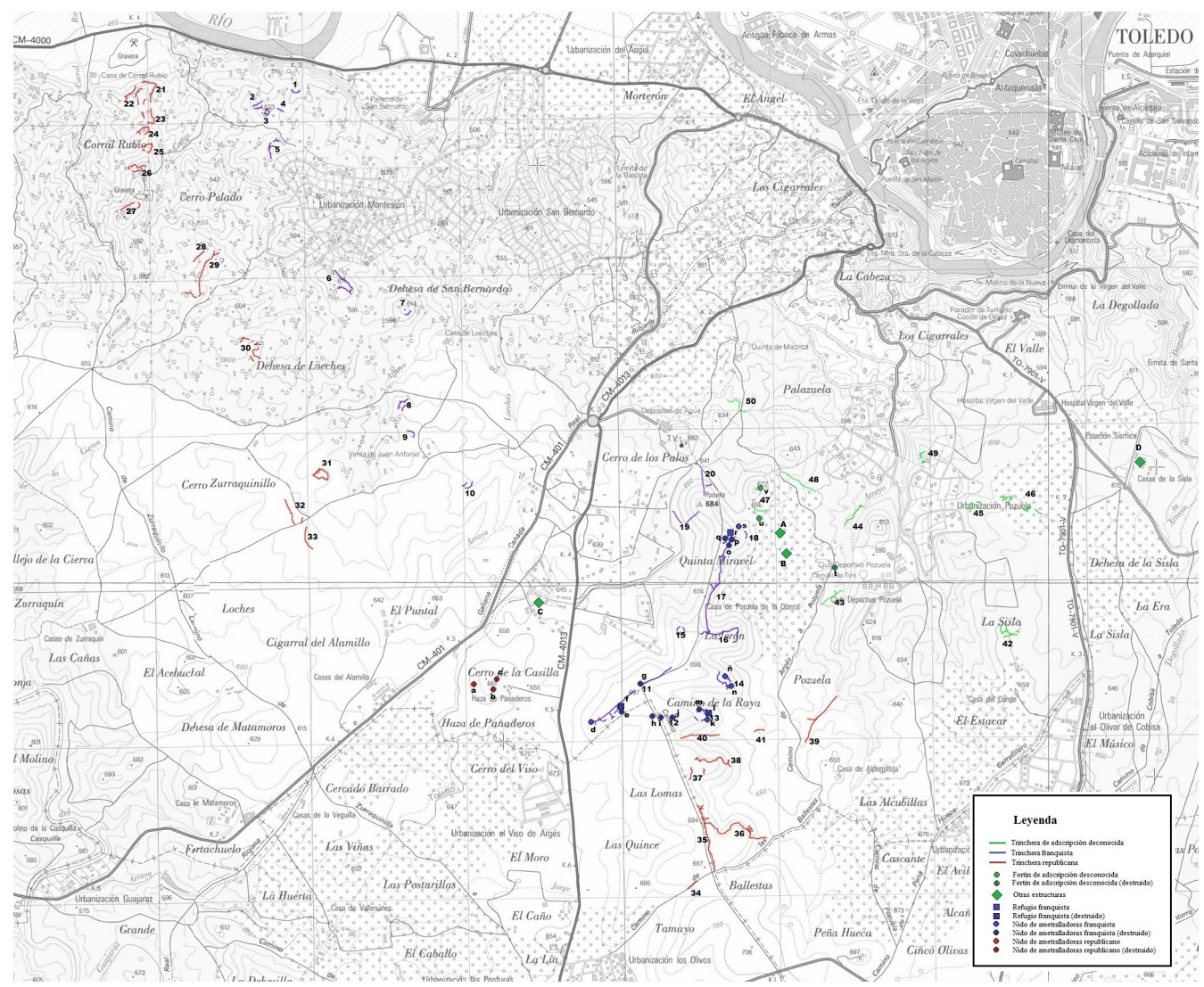

Fig. 5. Estructuras documentadas.

\section{Trincheras}

Se listan aquí las trincheras de primera línea halladas, numeradas en sentido antihorario, desde las inmediaciones del Tajo, a la altura de los kilómetros 3-4 de la CM-4000 (carrtera Toledo-La Puebla de Montalbán), hasta la Urbanización Pozuela, al suroeste del Hospital Virgen del Valle. La atribución de la trinchera a uno de los bandos se basa en planimetría encontrada en el Archivo General Militar de Ávila. Se indican también las correspondencias con las trincheras prospectadas en 2010-2011 y con los yacimientos enumerados en la Carta Arqueológica de Toledo. 


\begin{tabular}{|c|c|c|c|}
\hline Trinchera & Ubicación & Descripción & $\begin{array}{l}\text { Material metálico } \\
\text { relevante }\end{array}$ \\
\hline $\mathrm{T} 2$ & $\begin{array}{l}\text { Ladera N } \\
\text { del Vértice } \\
\text { Pozuela }\end{array}$ & $\begin{array}{l}\text { Sentido N-S. } 203 \text { m. en línea recta. } 30-50 \mathrm{cms} \\
\text { de profundidad en su parte menos colmatada. } \\
\text { Posible puesto de tirador en su unión con la T3. } \\
\text { Interrumpida por el camino que recorre el cerro } \\
\text { por su base. }\end{array}$ & \multirow[t]{2}{*}{$\begin{array}{l}\text { Culotes de cartucho } \\
\text { de escopeta cal. } 12 . \\
\text { Proyectiles para máuser } \\
7 \text { mm, deformados por } \\
\text { el impacto. }\end{array}$} \\
\hline T3 & $\begin{array}{l}\text { Ladera N } \\
\text { del Vértice } \\
\text { Pozuela }\end{array}$ & $\begin{array}{l}\text { Bien perfilada. Parapeto más alto que talud, } \\
\text { orientada al N. } 43 \mathrm{~m} \text { de longitud, } 50 \mathrm{cms} \text { de } \\
\text { profundidad.Posible refugio/almacén en su zona } \\
\text { media. }\end{array}$ & \\
\hline T6 & $\begin{array}{l}\text { Ladera E del } \\
\text { Cerro Las } \\
\text { Lomas }\end{array}$ & $\begin{array}{l}\text { Pequeña trinchera en forma de media luna con } \\
\text { un puesto de escucha/observación avanzado } \\
\text { en uno de sus extremos. Frente a ella aparecen } \\
\text { restos de posibles trincheras republicanas. }\end{array}$ & \multirow{2}{*}{$\begin{array}{l}\text { Gran cantidad de } \\
\text { proyectiles de } 9 \text { mm, } \\
\text { muchos de ellos } \\
\text { impactados. Balas de } \\
\text { pistola impactadas, } 9 \\
\text { mm. Cola de proyectil } \\
\text { de mortero Brandt } \\
\text { de } 81 \text { mm. Peines y } \\
\text { vainas abundantes, } \\
\text { algunos con cartuchos } \\
\text { sin percutir. Munición } \\
\text { abundante de máuser } \\
7 \text { mm., española y } \\
\text { alemana con diversos } \\
\text { marcajes. Munición de } \\
\text { Lebel } 8 \text { mm. francesa. } \\
\text { Latas de conservas. } \\
\text { Fragmentos de proyectil } \\
\text { antiaéreo. }\end{array}$} \\
\hline T7 & $\begin{array}{l}\text { Ladera E del } \\
\text { Cerro Las } \\
\text { Lomas }\end{array}$ & $\begin{array}{l}\text { Trinchera muy larga ( } 700 \mathrm{~m} \text {.) en zigzag. Al menos } \\
3 \text { desvíos a puestos de tirador. } 4 \text { estructuras de } \\
\text { hormigón en su parte } \mathrm{N} \text {, una de ellas de gran } \\
\text { tamaño y en buen estado de conservación. } \\
\text { Estado de conservación aceptable, colmatación } \\
\text { variable. Frente a ella aparecen restos de posibles } \\
\text { trincheras republicanas. }\end{array}$ & \\
\hline T9 & $\begin{array}{l}\text { Caras N y } \\
\text { E del Cerro } \\
\text { Laderón }\end{array}$ & $\begin{array}{l}\text { Trinchera en torno al cerro, } 330 \mathrm{~m} \text {. de longitud. } \\
\text { Varios desdvíos. Mal estado de conservación } \\
\text { salvo en la zona Este, la más compleja, con un } \\
\text { posible almacén/refugio. Paredes de trinchera } \\
\text { engrosadas en el ángulo NE. }\end{array}$ & $\begin{array}{l}\text { Bala impactada } \\
\text { de máuser } 7 \text { mm. } \\
\text { Abundantes vainas y } \\
\text { cartuchos completos de } \\
\text { máuser } 7 \text { mm., español } \\
\text { y alemán. Vaina de } \\
\text { Carcano italiano de } 6,5 \\
\text { mm. Vaina de Lebel } 8 \\
\text { mm. Vaina de máuser } \\
\text { mexicano, importado } \\
\text { por el gobierno de la } \\
\text { República. Refuerzo de } \\
\text { bota militar. Lata. }\end{array}$ \\
\hline T10 & $\begin{array}{l}\text { Camino de } \\
\text { Las Lomas }\end{array}$ & $\begin{array}{l}\text { Lineal en principio, luego semicircular. } 230 \\
\text { m. de longitud. Buen estado en la parte lineal, } \\
\text { desdibujada en la semicircular. Escombros en } \\
\text { abundancia por la cercanía de viviendas. }\end{array}$ & $\begin{array}{l}\text { Peines de } r \text { máuser } \\
7 \quad \mathrm{~mm}, \quad \text { marcajes } \\
\text { ilegibles. }\end{array}$ \\
\hline
\end{tabular}




\begin{tabular}{|c|c|c|c|}
\hline Trinchera & Ubicación & Descripción & $\begin{array}{l}\text { Material metálico } \\
\text { relevante }\end{array}$ \\
\hline $\mathrm{T} 12$ & $\begin{array}{l}\text { Sur del } \\
\text { Laderón }\end{array}$ & $\begin{array}{l}\text { Ramal principal que se subdivide en el extremo } \\
\text { hacia varios puestos de tirador y emplazamiento } \\
\text { de arma automática. } 140 \mathrm{~m} \text {. de longitud. } \\
\text { No presenta excesiva colmatación, buena } \\
\text { conservación. Posible abrigo/refugio a mitad de } \\
\text { la trinchera. Nido de ametralladora de hormigón } \\
\text { en la parte frontal, muy colmatado. }\end{array}$ & \\
\hline T13 & $\begin{array}{l}\text { Sur del } \\
\text { Laderón }\end{array}$ & $\begin{array}{l}\text { Pequeña trinchera con ramales junto a la anterior. } \\
\text { Posible nido de ametralladora de hormigón en la } \\
\text { parte N. }\end{array}$ & \\
\hline $\mathrm{T} 14$ & $\begin{array}{l}\text { E del Cerro } \\
\text { de las } \\
\text { Rivillas }\end{array}$ & \multirow{2}{*}{$\begin{array}{l}\text { Trincheras que en su origen pudieron tener } \\
\text { forma circular, formando parte del mismo } \\
\text { complejo; con dos puestos de arma automática } \\
\text { (uno colmatado, el otro sin techado) y una } \\
\text { estructura de hormigón sin identificar. Bastante } \\
\text { desdibujada, sobre todo en la ladera S. Tres } \\
\text { puestos de armas automáticas cercanos, al O, } \\
\text { cubriendo el camino de Las Lomas y el Arroyo } \\
\text { Pozuela. }\end{array}$} & \\
\hline T15 & $\begin{array}{l}\text { SO del } \\
\text { Cerro de las } \\
\text { Rivillas }\end{array}$ & & \\
\hline $\mathrm{T} 17$ & $\begin{array}{l}\text { O de Las } \\
\text { Lomas }\end{array}$ & $\begin{array}{l}\text { Dos posiciones unidas por una trinchera recta, } \\
\text { más profunda, posiblemente de desplazamiento. } \\
\text { Estructuras derruídas de un nido de ametralladora } \\
\text { y otros elementos sin identificar. Posible puesto } \\
\text { de mando. Dos emplazamientos de armas } \\
\text { automáticas con varios puestos de tirador. } \\
\text { Posibles almacenes o refugios tras la trinchera. } \\
\text { Concentración de impactos de artillería en el } \\
\text { flanco N, algunos en la propia trinchera. }\end{array}$ & $\begin{array}{l}\text { Gran concentración } \\
\text { de metralla y } \\
\text { fragmentos proyectiles } \\
\text { artillería, entre ellos } \\
\text { de espoleta soviética } \\
\text { de } 45 \text { mm., } 114 \text { mm } \\
\text { y abundantes bandas } \\
\text { de reforzamiento. } \\
\text { Peines máuser español } \\
\text { y alemán de } 7 \text { y } 7,92 \\
\text { mm. Abundantes } \\
\text { vainas y cartuchos } \\
\text { máuser español } 7 \text { mm, } \\
\text { indeterminado } 7 \text { mm. } \\
\text { y alemán } 7,92 \text { mm. } \\
\text { Proyectiles impactados } \\
7 \text { mm. Cartucho Lebel } 8 \\
\text { mm. Latas de conservas, } \\
\text { fragmento cuchara, } \\
\text { hebilla, fragmentos de } \\
\text { vidrio. }\end{array}$ \\
\hline $\mathrm{T} 20$ & \multirow{2}{*}{$\begin{array}{l}\text { Cerro al SE } \\
\text { del anterior. }\end{array}$} & \multirow{2}{*}{$\begin{array}{l}\text { Conjunto de trincheras complementario a los } \\
\text { anteriores. Trinchera larga a lo largo de la curva } \\
\text { de nivel ladera N hasta posición avanzada con } \\
\text { pozos de tirador. Mal estado, desdibujadas. }\end{array}$} & \\
\hline $\mathrm{T} 22$ & & & \\
\hline $\mathrm{T} 23$ & $\begin{array}{l}\text { Cruce } \\
\text { Camino Las } \\
\text { Lomas con } \\
\text { actual CM- } \\
40\end{array}$ & $\begin{array}{l}\text { Destruída en su mayor parte por las obras de la } \\
\text { CM-40. Consta en fotos aéreas hasta } 2010 .\end{array}$ & \\
\hline
\end{tabular}




\begin{tabular}{|l|l|l|c|}
\hline Trinchera & Ubicación & \multicolumn{1}{|c|}{ Descripción } & \multicolumn{1}{c|}{$\begin{array}{c}\text { Material metálico } \\
\text { relevante }\end{array}$} \\
\hline T24 & $\begin{array}{l}\text { Camino de } \\
\text { Las Lomas } \\
- \text { Cruce de } \\
\text { camino Las } \\
\text { Ballestas }\end{array}$ & $\begin{array}{l}\text { Bien perfiladas, no colmatadas, pero abundante } \\
\text { presencia de escombros por las cercanías de } \\
\text { Argés. 440 m. de largo con al menos 2 trincheras } \\
\text { secundarias con sendos puestos de observación/ } \\
\text { pozos de tirador en el flanco E. }\end{array}$ & \\
\hline
\end{tabular}

\section{Fortines}

Antes de proceder al inventario de los fortines y estructuras defensivas de hormigón hay que tener en cuenta que la erección de este tipo de edificaciones en la zona son tardías en cuanto al curso de la Guerra Civil, remontándose en su mayoría a fechas posteriores a diciembre de 1938.

\begin{tabular}{|c|c|c|c|}
\hline Trinchera & Ubicación & Descripción & $\begin{array}{l}\text { Material metálico } \\
\text { relevante }\end{array}$ \\
\hline $\mathrm{T} 2$ & $\begin{array}{l}\text { Ladera N } \\
\text { del Vértice } \\
\text { Pozuela }\end{array}$ & $\begin{array}{l}\text { Sentido N-S. } 203 \mathrm{~m} \text {. en línea recta. } 30-50 \mathrm{cms} \\
\text { de profundidad en su parte menos colmatada. } \\
\text { Posible puesto de tirador en su unión con la T3. } \\
\text { Interrumpida por el camino que recorre el cerro } \\
\text { por su base. }\end{array}$ & \multirow[t]{2}{*}{$\begin{array}{l}\text { Culotes de cartucho } \\
\text { de escopeta cal. } 12 \text {. } \\
\text { Proyectiles para máuser } \\
7 \mathrm{~mm} \text {, deformados por } \\
\text { el impacto. }\end{array}$} \\
\hline T3 & $\begin{array}{l}\text { Ladera N } \\
\text { del Vértice } \\
\text { Pozuela }\end{array}$ & $\begin{array}{l}\text { Bien perfilada. Parapeto más alto que talud, } \\
\text { orientada al N. } 43 \mathrm{~m} \text { de longitud, } 50 \mathrm{cms} \text { de } \\
\text { profundidad.Posible refugio/almacén en su zona } \\
\text { media. }\end{array}$ & \\
\hline T6 & $\begin{array}{l}\text { Ladera E del } \\
\text { Cerro Las } \\
\text { Lomas }\end{array}$ & $\begin{array}{l}\text { Pequeña trinchera en forma de media luna con } \\
\text { un puesto de escucha/observación avanzado } \\
\text { en uno de sus extremos. Frente a ella aparecen } \\
\text { restos de posibles trincheras republicanas. }\end{array}$ & \multirow{2}{*}{$\begin{array}{l}\text { Gran cantidad de } \\
\text { proyectiles de } 9 \text { mm, } \\
\text { muchos de ellos } \\
\text { impactados. Balas de } \\
\text { pistola impactadas, } 9 \\
\text { mm. Cola de proyectil } \\
\text { de mortero Brandt } \\
\text { de } 81 \text { mm. Peines y } \\
\text { vainas abundantes, } \\
\text { algunos con cartuchos } \\
\text { sin percutir. Munición } \\
\text { abundante de máuser } \\
7 \text { mm., española y } \\
\text { alemana con diversos } \\
\text { marcajes. Munición de } \\
\text { Lebel } 8 \text { mm. francesa. } \\
\text { Latas de conservas. } \\
\text { Fragmentos de proyectil } \\
\text { antiaéreo. }\end{array}$} \\
\hline T7 & $\begin{array}{l}\text { Ladera E del } \\
\text { Cerro Las } \\
\text { Lomas }\end{array}$ & $\begin{array}{l}\text { Trinchera muy larga ( } 700 \mathrm{~m} \text {.) en zigzag. Al menos } \\
3 \text { desvíos a puestos de tirador. } 4 \text { estructuras de } \\
\text { hormigón en su parte } \mathrm{N} \text {, una de ellas de gran } \\
\text { tamaño y en buen estado de conservación. } \\
\text { Estado de conservación aceptable, colmatación } \\
\text { variable. Frente a ella aparecen restos de posibles } \\
\text { trincheras republicanas. }\end{array}$ & \\
\hline
\end{tabular}




\begin{tabular}{|c|c|c|c|}
\hline Trinchera & Ubicación & Descripción & $\begin{array}{l}\text { Material metálico } \\
\text { relevante }\end{array}$ \\
\hline T9 & $\begin{array}{l}\text { Caras } \mathrm{N} \text { y } \\
\text { E del Cerro } \\
\text { Laderón }\end{array}$ & $\begin{array}{l}\text { Trinchera en torno al cerro, } 330 \text { m. de longitud. } \\
\text { Varios desdvíos. Mal estado de conservación } \\
\text { salvo en la zona Este, la más compleja, con un } \\
\text { posible almacén/refugio. Paredes de trinchera } \\
\text { engrosadas en el ángulo NE. }\end{array}$ & $\begin{array}{l}\text { Bala impactada } \\
\text { de máuser } 7 \text { mm. } \\
\text { Abundantes vainas y } \\
\text { cartuchos completos de } \\
\text { máuser } 7 \mathrm{~mm} \text {., español } \\
\text { y alemán. Vaina de } \\
\text { Carcano italiano de } 6,5 \\
\text { mm. Vaina de Lebel } 8 \\
\text { mm. Vaina de máuser } \\
\text { mexicano, importado } \\
\text { por el gobierno de la } \\
\text { República. Refuerzo de } \\
\text { bota militar. Lata. }\end{array}$ \\
\hline $\mathrm{T} 10$ & $\begin{array}{l}\text { Camino de } \\
\text { Las Lomas }\end{array}$ & $\begin{array}{l}\text { Lineal en principio, luego semicircular. } 230 \\
\text { m. de longitud. Buen estado en la parte lineal, } \\
\text { desdibujada en la semicircular. Escombros en } \\
\text { abundancia por la cercanía de viviendas. }\end{array}$ & $\begin{array}{lr}\text { Peines de } & \text { máuser } \\
7 \quad \text { mm, } & \text { marcajes } \\
\text { ilegibles. } & \text { Vainas } \\
\text { de máuser español } \\
\text { e indeterminado. } \\
\text { Proyectiles ojivales de } \\
\text { máuser } 7 \text { mm. }\end{array}$ \\
\hline T12 & $\begin{array}{l}\text { Sur del } \\
\text { Laderón }\end{array}$ & $\begin{array}{l}\text { Ramal principal que se subdivide en el extremo } \\
\text { hacia varios puestos de tirador y emplazamiento } \\
\text { de arma automática. } 140 \mathrm{~m} \text {. de longitud. } \\
\text { No presenta excesiva colmatación, buena } \\
\text { conservación. Posible abrigo/refugio a mitad de } \\
\text { la trinchera. Nido de ametralladora de hormigón } \\
\text { en la parte frontal, muy colmatado. }\end{array}$ & \\
\hline T13 & $\begin{array}{l}\text { Sur del } \\
\text { Laderón }\end{array}$ & $\begin{array}{l}\text { Pequeña trinchera con ramales junto a la anterior. } \\
\text { Posible nido de ametralladora de hormigón en la } \\
\text { parte } \mathrm{N} \text {. }\end{array}$ & \\
\hline $\mathrm{T} 14$ & $\begin{array}{l}\text { E del Cerro } \\
\text { de las } \\
\text { Rivillas }\end{array}$ & \multirow{2}{*}{$\begin{array}{l}\text { Trincheras que en su origen pudieron tener } \\
\text { forma circular, formando parte del mismo } \\
\text { complejo; con dos puestos de arma automática } \\
\text { (uno colmatado, el otro sin techado) y una } \\
\text { estructura de hormigón sin identificar. Bastante } \\
\text { desdibujada, sobre todo en la ladera S. Tres } \\
\text { puestos de armas automáticas cercanos, al O, } \\
\text { cubriendo el camino de Las Lomas y el Arroyo } \\
\text { Pozuela. }\end{array}$} & \\
\hline T15 & $\begin{array}{l}\text { SO del } \\
\text { Cerro de las } \\
\text { Rivillas }\end{array}$ & & \\
\hline
\end{tabular}




\begin{tabular}{|c|c|c|c|}
\hline Trinchera & Ubicación & Descripción & $\begin{array}{l}\text { Material metálico } \\
\text { relevante }\end{array}$ \\
\hline T17 & $\begin{array}{l}\text { O de Las } \\
\text { Lomas }\end{array}$ & $\begin{array}{l}\text { Dos posiciones unidas por una trinchera recta, } \\
\text { más profunda, posiblemente de desplazamiento. } \\
\text { Estructuras derruídas de un nido de ametralladora } \\
\text { y otros elementos sin identificar. Posible puesto } \\
\text { de mando. Dos emplazamientos de armas } \\
\text { automáticas con varios puestos de tirador. } \\
\text { Posibles almacenes o refugios tras la trinchera. } \\
\text { Concentración de impactos de artillería en el } \\
\text { flanco N, algunos en la propia trinchera. }\end{array}$ & $\begin{array}{l}\text { Gran concentración de } \\
\text { metralla y fragmentos } \\
\text { proyectiles artillería, } \\
\text { entre ellos de espoleta } \\
\text { soviética de } 45 \text { mm., } \\
114 \mathrm{~mm} \text { y abundantes } \\
\text { bandas de reforzamiento. } \\
\text { Peines máuser español } \\
\text { y alemán de } 7 \text { y } 7,92 \\
\text { mm. Abundantes } \\
\text { vainas y cartuchos } \\
\text { máuser español } 7 \mathrm{~mm} \text {, } \\
\text { indeterminado } 7 \text { mm. } \\
\text { y alemán } 7,92 \text { mm. } \\
\text { Proyectiles impactados } \\
7 \text { mm. Cartucho Lebel } 8 \\
\text { mm. Latas de conservas, } \\
\text { fragmento cuchara, } \\
\text { hebilla, fragmentos de } \\
\text { vidrio. }\end{array}$ \\
\hline T20 & \multirow{2}{*}{$\begin{array}{l}\text { Cerro al SE } \\
\text { del anterior. }\end{array}$} & \multirow{2}{*}{$\begin{array}{l}\text { Conjunto de trincheras complementario a los } \\
\text { anteriores. Trinchera larga a lo largo de la curva } \\
\text { de nivel ladera } \mathrm{N} \text { hasta posición avanzada con }\end{array}$} & \\
\hline T22 & & & \\
\hline T23 & $\begin{array}{l}\text { Cruce } \\
\text { Camino Las } \\
\text { Lomas con } \\
\text { actual CM-40 } \\
\end{array}$ & $\begin{array}{l}\text { Dozos de tirador. Mal estado, desdibujadas. } \\
\text { Destruida en su mayor parté por las obras de la } \\
\text { CM- } 40 \text {. Consta en fotos aéreas hasta } 2010 .\end{array}$ & \\
\hline T24 & $\begin{array}{l}\text { Camino de } \\
\text { Las Lomas } \\
- \text { Cruce de } \\
\text { camino Las } \\
\text { Ballestas }\end{array}$ & $\begin{array}{l}\text { Bien perfiladas, no colmatadas, pero abundante } \\
\text { presencia de escombros por las cercanías de } \\
\text { Argés. } 440 \mathrm{~m} \text {. de largo con al menos } 2 \text { trincheras } \\
\text { secundarias con sendos puestos de observación/ } \\
\text { pozos de tirador en el flanco E. }\end{array}$ & \\
\hline
\end{tabular}

\section{Otras estructuras}

\begin{tabular}{|c|c|c|c|}
\hline Trinchera & Ubicación & Descripción & $\begin{array}{l}\text { Material metálico } \\
\text { relevante }\end{array}$ \\
\hline $\mathrm{T} 2$ & $\begin{array}{l}\text { Ladera N } \\
\text { del Vértice } \\
\text { Pozuela }\end{array}$ & $\begin{array}{l}\text { Sentido N-S. } 203 \mathrm{~m} \text {. en línea recta. } 30-50 \mathrm{cms} \\
\text { de profundidad en su parte menos colmatada. } \\
\text { Posible puesto de tirador en su unión con la T3. } \\
\text { Interrumpida por el camino que recorre el cerro } \\
\text { por su base. }\end{array}$ & \multirow[t]{2}{*}{$\begin{array}{l}\text { Culotes de cartucho } \\
\text { de escopeta cal. } \\
12 \text { Proyectiles } \\
\text { para máuser } 7 \mathrm{~mm} \text {, } \\
\text { deformados por el } \\
\text { impacto. }\end{array}$} \\
\hline T3 & $\begin{array}{l}\text { Ladera N } \\
\text { del Vértice } \\
\text { Pozuela }\end{array}$ & $\begin{array}{l}\text { Bien perfilada. Parapeto más alto que talud, } \\
\text { orientada al N. } 43 \mathrm{~m} \text { de longitud, } 50 \mathrm{cms} \text { de } \\
\text { profundidad.Posible refugio/almacén en su zona } \\
\text { media. }\end{array}$ & \\
\hline
\end{tabular}




\begin{tabular}{|c|c|c|c|}
\hline Trinchera & Ubicación & Descripción & $\begin{array}{l}\text { Material metálico } \\
\text { relevante }\end{array}$ \\
\hline T6 & $\begin{array}{l}\text { Ladera E del } \\
\text { Cerro Las } \\
\text { Lomas }\end{array}$ & $\begin{array}{l}\text { Pequeña trinchera en forma de media luna con } \\
\text { un puesto de escucha/observación avanzado } \\
\text { en uno de sus extremos. Frente a ella aparecen } \\
\text { restos de posibles trincheras republicanas. }\end{array}$ & \multirow{2}{*}{$\begin{array}{l}\text { Gran cantidad de } \\
\text { proyectiles de } 9 \\
\text { mm, muchos de } \\
\text { ellos impactados. } \\
\text { Balas de pistola } \\
\text { impactadas, } 9 \text { mm. } \\
\text { Cola de proyectil de } \\
\text { mortero Brandt de } 81 \\
\text { mm. Peines y vainas } \\
\text { abundantes, algunos } \\
\text { con cartuchos sin } \\
\text { percutir. Munición } \\
\text { abundante de máuser } \\
7 \text { mm., española } \\
\text { y alemana con } \\
\text { diversos marcajes. } \\
\text { Munición de Lebel } \\
8 \text { mm. francesa. } \\
\text { Latas de conservas. } \\
\text { Fragmentos de } \\
\text { proyectil antiaéreo. }\end{array}$} \\
\hline T7 & $\begin{array}{l}\text { Ladera E del } \\
\text { Cerro Las } \\
\text { Lomas }\end{array}$ & $\begin{array}{l}\text { Trinchera muy larga ( } 700 \mathrm{~m} \text {.) en zigzag. Al menos } \\
3 \text { desvíos a puestos de tirador. } 4 \text { estructuras de } \\
\text { hormigón en su parte } \mathrm{N} \text {, una de ellas de gran } \\
\text { tamaño y en buen estado de conservación. } \\
\text { Estado de conservación aceptable, colmatación } \\
\text { variable. Frente a ella aparecen restos de posibles } \\
\text { trincheras republicanas. }\end{array}$ & \\
\hline T9 & $\begin{array}{l}\text { Caras N y } \\
\text { E del Cerro } \\
\text { Laderón }\end{array}$ & $\begin{array}{l}\text { Trinchera en torno al cerro, } 330 \mathrm{~m} \text {. de longitud. } \\
\text { Varios desdvíos. Mal estado de conservación } \\
\text { salvo en la zona Este, la más compleja, con un } \\
\text { posible almacén/refugio. Paredes de trinchera } \\
\text { engrosadas en el ángulo NE. }\end{array}$ & $\begin{array}{l}\text { Bala impactada } \\
\text { de máuser } 7 \text { mm. } \\
\text { Abundantes vainas y } \\
\text { cartuchos completos } \\
\text { de máuser } 7 \text { mm., } \\
\text { español y alemán. } \\
\text { Vaina de Carcano } \\
\text { italiano de } 6,5 \mathrm{~mm} \text {. } \\
\text { Vaina de Lebel } \\
8 \text { mm. Vaina de } \\
\text { máuser mexicano, } \\
\text { importado por el } \\
\text { gobierno de la } \\
\text { República. Refuerzo } \\
\text { de bota militar. Lata. }\end{array}$ \\
\hline $\mathrm{T} 10$ & $\begin{array}{l}\text { Camino de } \\
\text { Las Lomas }\end{array}$ & $\begin{array}{l}\text { Lineal en principio, luego semicircular. } 230 \\
\text { m. de longitud. Buen estado en la parte lineal, } \\
\text { desdibujada en la semicircular. Escombros en } \\
\text { abundancia por la cercanía de viviendas. }\end{array}$ & $\begin{array}{l}\text { Peines de máuser } \\
7 \quad \text { mm, marcajes } \\
\text { ilegibles. Vainas } \\
\text { de máuser español } \\
\text { e indeterminado. } \\
\text { Proyectiles ojivales } \\
\text { de máuser } 7 \mathrm{~mm} \text {. }\end{array}$ \\
\hline $\mathrm{T} 12$ & $\begin{array}{l}\text { Sur del } \\
\text { Laderón }\end{array}$ & $\begin{array}{l}\text { Ramal principal que se subdivide en el extremo } \\
\text { hacia varios puestos de tirador y emplazamiento } \\
\text { de arma automática. } 140 \mathrm{~m} \text {. de longitud. } \\
\text { No presenta excesiva colmatación, buena } \\
\text { conservación. Posible abrigo/refugio a mitad de } \\
\text { la trinchera. Nido de ametralladora de hormigón } \\
\text { en la parte frontal, muy colmatado. }\end{array}$ & \\
\hline
\end{tabular}




\begin{tabular}{|c|c|c|c|}
\hline Trinchera & Ubicación & Descripción & $\begin{array}{l}\text { Material metálico } \\
\text { relevante }\end{array}$ \\
\hline T13 & $\begin{array}{l}\text { Sur del } \\
\text { Laderón }\end{array}$ & $\begin{array}{l}\text { Pequeña trinchera con ramales junto a la anterior. } \\
\text { Posible nido de ametralladora de hormigón en la } \\
\text { parte N. }\end{array}$ & \\
\hline T14 & $\begin{array}{l}\text { E del Cerro } \\
\text { de las } \\
\text { Rivillas }\end{array}$ & \multirow{2}{*}{$\begin{array}{l}\text { Trincheras que en su origen pudieron tener } \\
\text { forma circular, formando parte del mismo } \\
\text { complejo; con dos puestos de arma automática } \\
\text { (uno colmatado, el otro sin techado) y una } \\
\text { estructura de hormigón sin identificar. Bastante } \\
\text { desdibujada, sobre todo en la ladera S. Tres } \\
\text { puestos de armas automáticas cercanos, al O, } \\
\text { cubriendo el camino de Las Lomas y el Arroyo } \\
\text { Pozuela. }\end{array}$} & \\
\hline T15 & $\begin{array}{l}\text { SO del } \\
\text { Cerro de las } \\
\text { Rivillas }\end{array}$ & & \\
\hline T17 & $\begin{array}{l}\text { O de Las } \\
\text { Lomas }\end{array}$ & $\begin{array}{l}\text { Dos posiciones unidas por una trinchera recta, } \\
\text { más profunda, posiblemente de desplazamiento. } \\
\text { Estructuras derruídas de un nido de ametralladora } \\
\text { y otros elementos sin identificar. Posible puesto } \\
\text { de mando. Dos emplazamientos de armas } \\
\text { automáticas con varios puestos de tirador. } \\
\text { Posibles almacenes o refugios tras la trinchera. } \\
\text { Concentración de impactos de artillería en el } \\
\text { flanco N, algunos en la propia trinchera. }\end{array}$ & 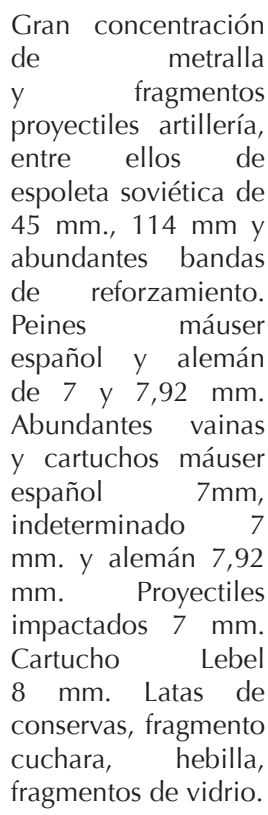 \\
\hline T20 & \multirow{2}{*}{$\begin{array}{l}\text { Cerro al SE } \\
\text { del anterior. }\end{array}$} & \multirow{2}{*}{$\begin{array}{l}\text { Conjunto de trincheras complementario a los } \\
\text { anteriores. Trinchera larga a lo largo de la curva } \\
\text { de nivel ladera } \mathrm{N} \text { hasta posición avanzada con } \\
\text { pozos de tirador. Mal estado, desdibujadas. }\end{array}$} & \\
\hline T22 & & & \\
\hline T23 & $\begin{array}{l}\text { Cruce } \\
\text { Camino Las } \\
\text { Lomas con } \\
\text { actual CM- } \\
40\end{array}$ & $\begin{array}{l}\text { Destruída en su mayor parte por las obras de la } \\
\text { CM- } 40 \text {. Consta en fotos aéreas hasta } 2010 .\end{array}$ & \\
\hline
\end{tabular}




\begin{tabular}{|l|l|l|l|}
\hline \multicolumn{1}{|c|}{ Trinchera } & \multicolumn{1}{|c|}{ Ubicación } & \multicolumn{1}{c|}{ Descripción } & $\begin{array}{c}\text { Material metálico } \\
\text { relevante }\end{array}$ \\
\hline T24 & $\begin{array}{l}\text { Camino de } \\
\text { Las Lomas } \\
- \text { Cruce de } \\
\text { camino Las } \\
\text { Ballestas }\end{array}$ & $\begin{array}{l}\text { Bien perfiladas, no colmatadas, pero abundante } \\
\text { presencia de escombros por las cercanías de } \\
\text { Argés. 440 m. de largo con al menos 2 trincheras } \\
\text { secundarias con sendos puestos de observación/ } \\
\text { pozos de tirador en el flanco E. }\end{array}$ & \\
\hline
\end{tabular}

\section{Amenazas y propuesta de musealización}

Los elementos listados más arriba constituyen un patrimonio amenazado. La desidia, el desconocimiento de los restos de la contienda bélica, su falta de consideración como elementos patrimoniales y la voracidad del crecimiento urbanístico son los vectores principales de la amenaza, que tienen como puntilla la considerable desprotección legal a la que se hayan sometidos. Lamentablemente, es tarde para salvar parte de este paisaje. Las obras de construcción de la variante CM-40, han causado la destrucción de parte del sistema de trincheras entre Argés y Pozuela sin ningún tipo de documentación previa. También, con posterioridad a la elaboración del presente trabajo, se ha tenido noticia de la instalación de una valla cinegética en la zona de la Quinta de Mirabel que imposibilita el acceso a los restos, así como de la destrucción de un tramo de trincheras del mismo sector para levantar una pista deportiva temporal. El primer paso de la protección del patrimonio es su conocimiento, y no solo por parte del mundo académico o especializado. Se propone, de este modo, un plan para una hipotética musealización de los escenarios descritos.

Para abordar cualquier proyecto similar en torno a la Batalla del Sur del Tajo se debería, en primer lugar, escoger un sector del frente para trabajar en él. Pese a que el campo de batalla no es extenso en comparación con otros de la guerra española, un frente de unos 15 kilómetros resultaría inabarcable para que una persona pueda recorrerlo cómodamente en una tarde o una mañana, el espacio temporal más adecuado para una visita.

La zona más adecuada para llevar a cabo ese hipotético proyecto de musealización sería la comprendida entre el Vértice Pozuela y el camino de la Raya en las inmediaciones de Argés, por varios factores: su relevancia histórica (fue en este sector, junto con la Dehesa de San Bernardo, en el noroeste, donde tuvieron lugar los combates más enconados de la batalla. Comprendidas en este área quedan las posiciones franquistas números 8 y 9, que cambiaron de manos varias veces a lo largo de los combates como se ha referido anteriormente); la alta concentración de vestigios (es el sector donde mayor número de estructuras asociadas a los combates se han localizado, y de índole 
más variada: trincheras, fortines, estructuras hidráulicas, etc.); el relativo buen estado de conservación de los mismos (A diferencia del sector noroccidental donde ha habido un notable crecimiento urbanístico, las posiciones al sur de Pozuela se han mantenido en gran medida intactas tras el conflicto); y el valor paisajístico (desde el vértice Pozuela se tiene una visión privilegiada tanto de la zona de monte bajo que precede a los Montes de Toledo -el resto del campo de batalla- como de la propia capital, con su impresionante panorámica medieval y renacentista). Habiendo acotado la zona de actuación se procedería a la excavación y documentación arqueológica de los puntos más relevantes, para obtener una sólida base sobre la que emprender posibles restauraciones y rehabilitaciones.

La tipología de la musealización podría atenerse a las premisas de un parque arqueológico. El recibimiento a los visitantes se haría a través de un pequeño museo de sitio que podría ubicarse antes del ascenso al Vértice Pozuela por su ladera oeste. Ese es el acceso natural a la zona a visitar, desde la carretera de Toledo a Argés. Se trata de una zona de parcelas con pequeñas viviendas de recreo, algunas de las cuales abandonadas o a medio terminar como segura consecuencia de la actual crisis inmobiliaria. Esto nos ofrece una oportunidad para adaptar alguna de estas construcciones como centro de bienvenida al visitante y museo de sitio. Asimismo se adaptarían para la visita una serie de puntos clave de la batalla, señalados en mapas y trípticos a disposición del turista.

El proyecto de musealización pretendería una paulatina inmersión en el ambiente de la batalla, siguiendo un curso narrativo inductivo, pasando de información general sobre el desarrollo de la Guerra Civil en la zona a los aspectos concretos de la batalla en sí.

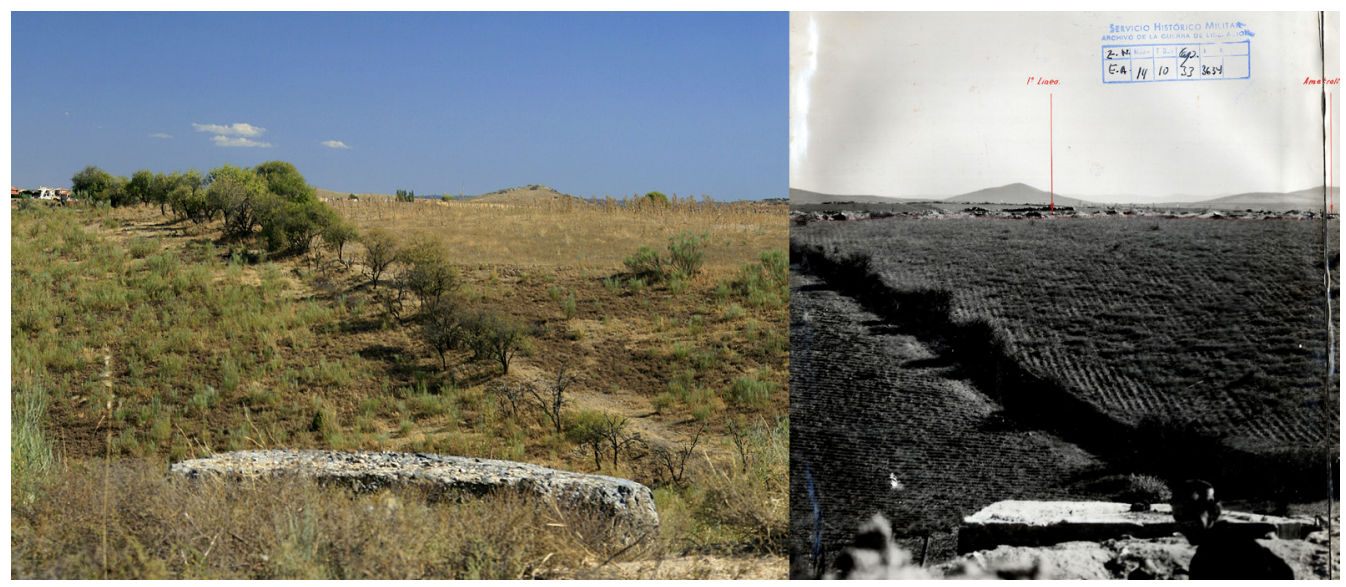

Fig. 6. Fortín trapeziodal frente a la Casa de la Pozuela, 1939 y 2011. 


\section{Elementos}

La primera parada sería el propio museo de sitio. Constaría de un aparcamiento y un centro de recepción al visitante, para lo que habría que acondicionar el área y asfaltar el camino de llegada hasta las cercanías de la ladera oeste del Vértice Pozuela. El museo estaría constituido por tres salas. La primera sería destinada a introducir a los visitantes en el contexto de los enfrentamientos. A través de textos, audiovisuales y material gráfico se explicaría de manera sucinta la marcha de la Guerra Civil hasta mayo de 1937, para a continuación hablar específicamente del conflicto en tierras toledanas y la constitución del Frente Sur del Tajo. La segunda sala se centraría específicamente en la Batalla del Sur del Tajo, hablando de los principales protagonistas, las fuerzas y planes enfrentados, la concepción de la acción y sus consecuencias, así como una breve mención a su desarrollo, que se vería completada al visitar las trincheras in situ. En la tercera y última sala la propuesta museística se complementaría con la reproducción a escala real de un tramo de trinchera de primera línea con el aspecto que debería tener durante los combates del Sur del Tajo, basándose en fotografías, informes, planimetría de la época así como empleando los resultados de la investigación arqueológica. Se emplearían reproducciones de armamento y utillería de la época, o incluso material original, pudiéndose contar incluso con alguno de los numerosos tanques soviéticos T-26 que se conservan aún en España (tres de ellos en la Academia de Infantería de Toledo), lo que podría contribuir a su preservación y restauración. La recreación de la trinchera se complementaría con efectos de iluminación y sonido, con el fin de favorecer la inmersión en el ambiente ${ }^{6}$. El museo de sitio sería el lugar perfecto para exponer los elementos más representativos hallados durante la excavación arqueológica, a través de los cuales se podría explicar no sólo el hecho bélico, sino la vida cotidiana de los combatientes a través de su cultura material.

El visitante, tras haberse formado una idea inicial con la información proporcionada en el museo, estaría listo para visitar los escenarios de la batalla. El recorrido no tendría por qué seguir un orden estricto, dejándose libertad al visitante para examinarlo a su gusto. Los espacios musealizados serían los siguientes:

1. El propio Vértice Pozuela, con placas explicativas sobre la importancia de esas alturas para la observación de Toledo. Dichas placas constarían de material gráfico que mostraría el aspecto de la capital Toledana durante la guerra, así como la ubicación de la Fábrica de Armas, objetivo de la artillería republicana y principal causa de la ofensiva franquista. El visitante podría comparar

\footnotetext{
6 Como ejemplos exitosos y rigurosos de reproducciones de escenarios bélicos con finalidad didáctica se pueden citar ejemplos tan dispares como el del Imperial War Museum de Londres, con sus recreaciones de una calle de la capital británica durante el Blitz y de una trinchera de la Primera Guerra Mundial en el frente del Somme; así como el Museo Panorama 1453 de Estambul, sobre la toma de Constantinopla.
} 
esa información con las actuales vistas de Toledo y reconocer los lugares más relevantes durante la guerra que aún perviven en su perfil urbano.

2. Las fortificaciones del cerro de la Mira. Las trincheras habrían sido limpiadas a fondo y restituído en la medida de lo posible de su profundidad original. Se habría emprendido la restauración de los búnkers del cerro, a los que el visitante podría tener acceso, con especial atención al impresionante refugio " $r$ " con sus paredes decoradas con grabados franquistas. Estas defensas correspondieron a la llamada "posición $\mathrm{n}^{\circ} 8^{\prime \prime}$, por lo que se procedería a la narración de los hechos bélicos aquí acaecidos.

3. Las trincheras y fortines del cerro de las Rivillas, números 12 y 13 (vid 2.1.). Estas trincheras nacionalistas se hallan enfrentadas a unas cercanas posiciones republicanas (trincheras 37, 38, 40 y 41), en ocasiones separadas por menos de un centenar de metros. En el Archivo General Militar de Ávila se ha localizado una panorámica fotográfica de gran interés tomada desde este mismo punto, lo que permitiría recrear con exactitud elementos como las alambradas y puestos de tirador, así como techumbres y otros elementos desaparecidos de las defensas de ambos bandos. La propia panorámica se podría insertar en un panel explicativo.

4. Trincheras y fortines junto al km 5 de la carretera Toledo-Argés (trinchera 11). En la rehabilitación de estas posiciones se pondría especial empeño en dejar visibles los cráteres producidos por la artillería republicana, que hablan por sí solos de la experiencia de quienes ocuparon las trincheras en los días del enfrentamiento. Esta zona constituyó parte de la famosa "posición $n^{\circ} 7^{\prime \prime}$, clave de la batalla, lo que se narraría en el correspondiente panel explicativo, acompañado de la descripción de los duros combates que aquí sostuvo la $6^{\text {a }}$ Bandera de la Legión.

\section{Bibliografía}

J. M. MARTÍNEZ BANDE, La batalla de Pozoblanco y el cierre de la bolsa de Mérida, en Monografías de la Guerra de España, n 15, Editorial San Martín, Madrid, 1981

J. M. RUIZ ALONSO, La guerra civil en la provincia de Toledo: Utopía, conflicto y poder en el sur del Tajo (1936 - 1939), Almud, Ciudad Real, 2004.

R. BARROSO CABRERA. et al. (2011): "Arqueología de la Guerra Civil en Toledo. El Frente Sur del Tajo y el Cigarral de Menores: un escenario de guerra", Archivo Secreto. Revista Cultural de Toledo, 5, pp. 330-348.

R. BARROSO CABRERA et al. (2014): La Guerra Civil en Toledo: El Frente Sur del Tajo. Metodología para el estudio de un frente de la guerra civil española, en VII Jornadas del Patrimonio Arqueológico de la Comunidad de Madrid (Madrid, 2010), Comunidad de Madrid, Madrid, 2014, pp. 
J. CARROBLES SANTOS y J. MORÍN DE PABLOS -eds.- (2014): Los paisajes culturales de la ciudad de Toledo. Dehesas, espacios irrigados, torres, cigarrales y trincheras. BAR Internacional Series 2638. Archaeopress, Oxford, 2014.

L.A. RUIZ CASERO (2014): Los combates al Sur del Tajo: Un enfoque patrimonial de un escenario de la Guerra Civil. AUDEMA, Madrid.

L.A.RUIZ CASERO (2015): Más allá del Alcázar. La batalla del sur del Tajo. Toledo y Argés, 1937. Silente, Guadalajara. 
